\title{
Juxtapapillary choroiditis in association with rising antichlamydial antibody
}

\author{
D. J. SPALTON, ${ }^{1}$ S. DAROUGAR, ${ }^{2}$ M. D. SANDERS, ${ }^{1}$ AND T. FORSEY ${ }^{2}$ \\ From the ${ }^{1}$ Medical Ophthalmology Unit, St Thomas's Hospital, London, and the ${ }^{2}$ Virus Laboratory, \\ Institute of Ophthalmology, London
}

SUMMARY We present the case of a 21-year-old girl with a uniocular juxtapapillary choroiditis. During the course of her illness the titre of antichlamydial IgG increased from 1/32 to 1/4096 against Chlamydia trachomatis TRIC serotypes $\mathrm{J}$ and $\mathrm{C}$, and antichlamydial IgM appeared in her blood. Toxoplasma dye test was positive at a level of $1 / 128$ but no increase in the titre of antibody was detected during the course of her infection. The relevance of these findings to her ocular lesion is discussed.

Peripapillary choroiditis was first described by Griffiths (1897), who indicated that the condition could be difficult to differentiate from papillitis. A series of 38 cases of choroiditis (Friedenwald, 1902) contained 10 with inflammation adjacent to the optic disc, but for some reason the description has been associated with Edmund-Jensen (1908) who published 4 cases.

Juxtapapillary choroiditis appears to differ only in its geographical location from other recognised forms of choroiditis. Toxoplasmosis has been reported as the most frequent cause of the disease on the grounds of rising titre of antitoxoplasma antibody in the blood (Duke-Elder, 1966). However, tuberculosis and streptococcal infections are also considered to be responsible for certain cases of choroidits.

We report here a case of juxtapapillary choroiditis in which the patient had serological evidence of an active chlamydial infection and discuss the relationship of this to her ocular condition.

\section{Case report}

A 21-year-old black. woman (born in France) presented with a history that 5 days previously she had noticed a transient redness and watering of the right eye. After this there was pain on eye movement, increasing blurring of vision, and superior field loss. Her left eye was amblyopic, she had been born prematurely at $6 \frac{1}{2}$ months and had received oxygen in an incubator for several weeks. Otherwise there

Correspondence to Mr D. J. Spalton, Medical Ophthalmology Unit, St Thomas's Hospital, London SEl were no significant features in her previous general health or ocular history. She was sexually active and had had an illegitimate baby 6 months previously.

On clinical examination her acuities were 6/18 correcting to $6 / 9$ in the right eye with a $-3 D$ lens and $1 / 60$ in the left with a $-16 \mathrm{D}$ lens. Examination of palpebral and bulbar conjunctivae and both anterior segments were normal; there were a few cells in the right vitreous, though the left was clear. The right optic disc was swollen with a white retinal and subretinal infiltration inferiorly (Fig. 1), and the disc and adjacent vessels leaked fluorescein (Fig. 2). Otherwise the fundus was normal. The left optic disc was highly myopic with traction of the vessels to an area of pigmentation and scarring along the temporal area consistent with a mild degree of retrolental fibroplasia in this eye.

She was admitted to hospital for thorough investigation in view of the fact that this was her only functional eye. General examination was normal. Skull and chest $x$-rays were normal. Haematology showed $\mathrm{Hb} 14 \cdot 1 \mathrm{~g} / \mathrm{dl}$, leucocytes $10 \cdot 3$ $\times 10^{2} / 1$ (neutrophils $67 \%$ ), erythrocyte sedimentation rate (ESR) $3 \mathrm{~mm} / \mathrm{h}$, fibrinogen $3.19 \mathrm{~g} / \mathrm{l}$, with a normal blood film and negative Paul-Bunnell test. Tests of renal and hepatic function were normal, as was the serum calcium. Cultures of the blood and urine grew no pathogens. Total protein was $62 \mathrm{~g} / 1$ (albumin $41 \mathrm{~g} / \mathrm{l}$ ), IgG $11.7 \mathrm{~g} / \mathrm{l}$, IgA $1.55 \mathrm{~g} / \mathrm{l}$, IgM $1.55 \mathrm{~g} / \mathrm{l}$, and $\mathrm{C}_{3} 1 \cdot 15 \mathrm{~g} / \mathrm{l}$. Autoantibodies were present to smooth muscle and mitochondria. The latex agglutination test was negative. No parasites were found in the faeces. The cerebrospinal fluid was normal, and serological tests for syphilis, 
including Treponema pallidum haemagglutination test, Venereal Disease Reference Laboratory flocculation test, and absorbed fluorescent treponemal antibody test were all negative.

She received a course of ACTH ( 80 units/day) for 5 days, which was then stopped. After this her leucocyte count rose to $14.7 \times 10^{9} / 1(56 \%$ netrophils $)$

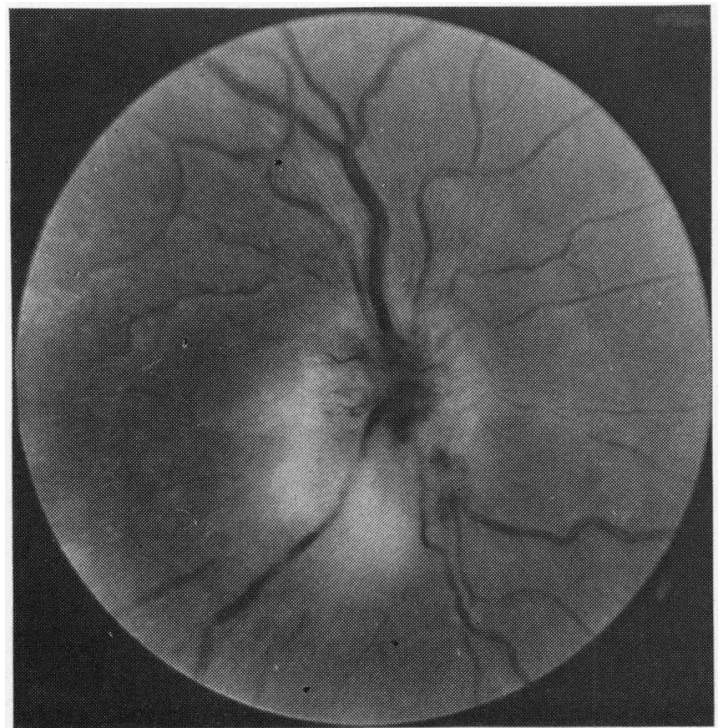

Fig. 1 Right optic disc showing retinal and subretinal exudation inferiorly

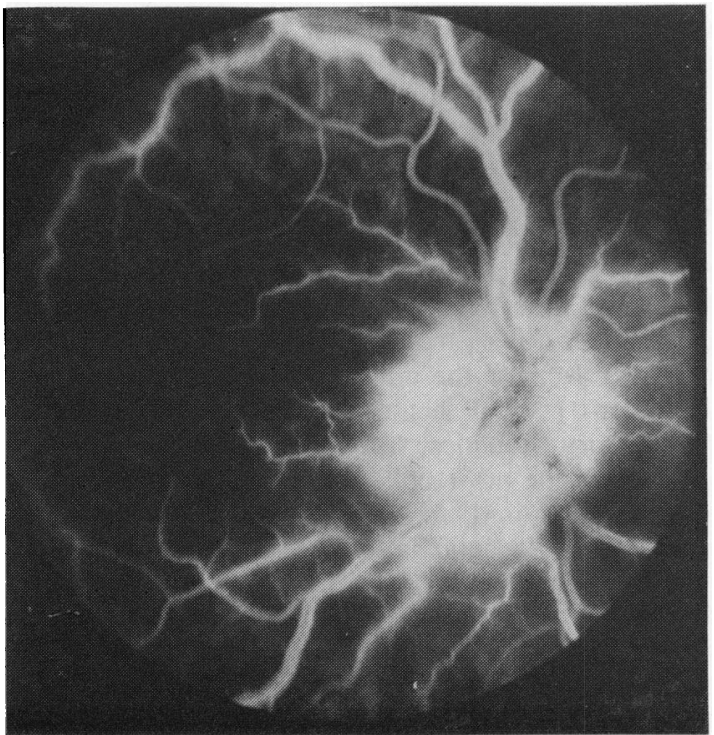

Fig. 2 Fluorescein angiogram of the right disc showing leakage of fluorescein from disc and vessels in the late stage and was $12 \cdot 7 \times 10^{9} / 15$ days after this. She complained of increasing visual loss about 2 weeks after admission, and prednisolone $60 \mathrm{mg} /$ day was recommenced. The white blood cell count rose to $23.8 \times 10^{9} / 1(79 \%$ neutrophils $)$ and slowly decreased to normal levels over the next 4 weeks.

No significant rise in antibody titre was found against herpes simplex, herpes zoster, cytomegalovirus, measles, mumps, adenovirus, influenza $\mathbf{A}+\mathbf{B}$, parainfluenza, respiratory syncytial virus, and hepatitis B. Antibody titres against mycoplasma, Rickettsia burnetti, Salmonella typhi, and Salm. paratyphi were not significant, and tests for toxocara were negative. A Mantoux test to 1:10000 PPD was negative. The toxoplasma dye test on a blood sample collected 2 weeks from the onset of infection showed titres of 1/128; no IgM antibody was present and a further specimen 2 weeks later did not show a rise in titre. The Kveim test was negative. Shortly after leaving hospital the patient failed to attend for follow-up.

Chlamydial serology by the modified micro-IF test (Treharne et al., 1977a) showed a significant rise in the titre of antichlamydial IgG from $1 / 32$ to $1 / 4096$ during the course of the disease and the presence of antichlamydial IgM at a titre of $1 / 16$ (Table 1). The highest IgG titre was against Chlamydia trachomatis TRIC serotypes $\mathbf{J}$ and $\mathrm{C}$.

Clinical examinations of the genital tract and abdomen showed no abnormality in the cervix,

Table 1 Detection of immunoglobulin class of antichlamydial antibody in the blood by a micro-IF test

\begin{tabular}{|c|c|c|c|c|c|c|}
\hline \multirow{2}{*}{$\begin{array}{l}\text { Chlamydiae } \\
\text { C. trachomatis }\end{array}$} & \multicolumn{2}{|c|}{$\begin{array}{l}18 \text { Dec. } 1977 \\
12 \text { days from } \\
\text { the onset }\end{array}$} & \multicolumn{2}{|c|}{$\begin{array}{l}12 \text { Jan. } 1978 \\
5 \text { weeks from } \\
\text { the onset }\end{array}$} & \multicolumn{2}{|c|}{$\begin{array}{l}2 \text { Feb. } 1978 \\
8 \text { weeks frcm } \\
\text { the onset }\end{array}$} \\
\hline & $\operatorname{Ig} G$ & $I g M$ & $\operatorname{Ig} G$ & $\operatorname{Ig} M$ & $I g G$ & $I g M$ \\
\hline$A$ & 32 & 0 & 256 & 16 & 32 & 0 \\
\hline$B$ & 32 & 0 & 256 & 16 & 32 & 0 \\
\hline$C$ & 32 & 0 & 4096 & 16 & 2048 & 0 \\
\hline$D$ & 0 & 0 & 2048 & 16 & 1024 & 0 \\
\hline$E$ & 0 & 0 & 2048 & 16 & 1024 & 0 \\
\hline$F$ & 0 & 0 & 2048 & 16 & 1024 & 0 \\
\hline$G$ & 0 & 0 & 2048 & 16 & 1024 & 0 \\
\hline$H$ & 0 & 0 & 2048 & 16 & 1024 & 0 \\
\hline$I$ & 0 & 0 & 2048 & 16 & 1024 & 0 \\
\hline$J$ & 32 & 0 & 4096 & 16 & 20.18 & 0 \\
\hline$K$ & 0 & 0 & 2048 & 16 & 1024 & 0 \\
\hline LGV I & 0 & 0 & 128 & 16 & 64 & 0 \\
\hline II & 0 & 0 & 128 & 16 & 64 & 0 \\
\hline III & 0 & 0 & 128 & 16 & 64 & 0 \\
\hline C. psittaci & 0 & 0 & 128 & 16 & 32 & 0 \\
\hline
\end{tabular}


urethra, rectum, or the Fallopian tubes. No chlamydiae were isolated from the cervix, and the micro-IF test on cervical secretion was negative for antichlamydial antibody. Culture of a blood sample collected 2 weeks after the onset of papillitis was sterile after 15 days' incubation. Urine culture produced no significant growth of bacteria.

\section{Discussion}

The development of blurred vision associated with pain in this patient, together with the absence of any previous chorioretinal scarring, suggested that her juxtapapillary lesion had been recently acquired and that it might be due to an active infection because of the increasing white blood cell count.

Serological evidence for infection by a wide variety of organisms was sought. Of these, the tests for chlamydiae and toxoplasma were positive. The micro-IF tests on a sample of blood collected 2 weeks after the onset of papillitis showed antichlamydial IgG at a level of $1 / 32$ against $C$. trachomatis TRIC serotypes A, B, C, and J. TRIC serotypes $\mathrm{A}, \mathrm{B}$, and $\mathrm{C}$ are generally associated with hyperendemic trachoma of eye-to-eye transmission, which is common in Asia and Africa, and TRIC serotype $\mathbf{J}$ is associated with chlamydial genital infection common in developed countries. The presence of IgG at a low level of 1/32 against these agents suggests that this patient may have been exposed to chlamydiae in the past or is at present suffering from a chlamydial infection.

The second sample of blood collected 3 weeks later ( 5 weeks after the onset of choroiditis) showed a rise in IgG titre to the very high value of $1 / 4096$ against $C$. trachomatis TRIC serotypes $\mathbf{J}$ and $\mathbf{C}$, and antichlamydial $\operatorname{IgM}$ at a titre of $1 / 16$. The significant rise in the titre of antichlamydial IgG and the presence of IgM during the course of the disease strongly suggests that our patient had an active chlamydial infection, probably due to TRIC serotypes $\mathbf{J}$ or $\mathbf{C}$.

TRIC serotype $\mathrm{J}$ is a member of the group which is associated with chlamydial genital infection in men and women, including non-specific urethritis in men, non-specific genital infection in women, pelvic inflammatory disease in women, and ocular TRIC infection of sexually transmitted origin (Treharne et al., 1977a, b) common in the developed countries of the Western world. Studies by Wang and Grayston (1975) and Treharne et al. (1977a) have shown that there is a strong serological crossreaction between TRIC serotype $C$ of hyperendemic trachoma and TRIC serotype $J$ of ocular-genital infections. However, from the epidemiological viewpoint it is likely that in our patient TRIC serotype $J$ may have been responsible for the infection rather than TRIC serotype C. The low level of IgG against LGV agents and $C$. psittaci detected in the blood of our patient may exclude these organisms as the cause of infection.

The very high titre of antichlamydial IgG obtained in this case is much higher than the average titre of antibody normally detected in patients with chlamydial urethritis or cervicitis (Treharne et al., 1977b), but it is within the range of the titres which have been obtained in patients with pelvic inflammatory disease (Treharne et al., 1979). In this patient clinical and laboratory investigations of the genital tract and abdomen revealed no evidence of chlamydial infection of the cervix or Fallopian tubes. However, these negative results cannot rule out the possibility of an occult urogenital chlamydial infection or a latent chlamydial pelvic infection, which might be responsible for the intraocular infection.

The role of chlamydiae in the production of human disease is being increasingly recognised. Recent studies have shown that $C$. trachomatis may cause systemic infection, that is, pneumonitis in newborn babies (Beem and Saxon, 1977), pelvic inflammatory disease (Mardh et al., 1977; Treharne et al., 1979), peritonitis, and perihepatitis in sexually active women (Muller-Shoop et al., 1978). C. trachomatis has been isolated from the cervix of 5 to $12 \%$ of women attending for routine prenatal examination with no obvious cervical inflammatory changes (Alexander et al., 1977) and in up to $31 \%$ of women attending sexually transmitted diseases clinic (Hilton et al., 1974).

The toxoplasma dye test was positive at a level of $1 / 128$ in the blood taken at 2 weeks after the onset of symptoms and 2 weeks later when the patient's choroiditis was well established. No IgM antibodies were found on either occasion, though the relevance of this to ocular infections is not known. These results must be interpreted with caution. Positive titres of $1 / 16$ or greater are found in up to $40 \%$ of the adult population and titres of $1 / 256$ in $1 \%$ of healthy adults (Public Health Laboratory Statistics, 1969).

It would be most unlikely that our patient had a recently acquired toxoplasmosis. This is a rare infection, and ocular invol: ement in the absence of systemic symptoms or signs is exceptionally rare. Furthermore, the dye test titres detected in this patient are too low to indicate such an active infection (Perkins, 1973). However, it is more difficult to exclude congenital toxoplasmosis as the cause of her ocular lesion. In some studies (Perkins, 1961) up to $96 \%$ of focal posterior choroiditis is attributed to this agent. In order to be certain of 
this diagnosis signs of previous chorioretinal scarring, intracranial calcification, and a rise in dye test titre should be demonstrated. However, occasionally histological evidence of ocular toxoplasmosis has been found in the presence of a negative dye test (Franceschetti and Englebrecht, 1964), and a fresh focal choroiditis with no evidence of previous scarring has been found with intracranial calcification on skull $x$-ray and a positive dye test (Perkins, 1973).

The result of our investigation suggests that the cause of our patient's disease is likely to be chlamydiae rather than toxoplasma. However, further investigations will be necessary to define whether or not chlamydial organisms do have a role in this disease.

We thank Mr R. Sennhenn for taking the photographs.

\section{References}

Alexander, E. R., Chandler, J., Phaifer, T. A., Wang, S. P., English, M., and Holmes, K. K. (1977). Prospective study of perinatal Chlamydia trachomatis infection. In Nongonococcal Urethritis and Related Infections, pp. 148-152. Edited by D. Hobson and K. K. Holmes. American Society for Microbiology: Washington.

Beem, M. O., and Saxon, E. M. (1977). Respiratory tract colonization and a distinctive pheunomia syndrome in infants infected with Chlamydia trachomatis. New England Journal of Medicine, 296, 306-310.

Duke-Elder, S. (1966). Diseases of the uveal tract. In System of Ophthalmology, Vol. 9.

Edmund-Jensen, E. (1908). Retino-choroiditis juxtapapillaris. Albrech von Graefes Archiv für Ophthalmologie, 69, 41-48.

Franceschetti, A., and Englebrecht, E. (1964). Mise en evidence de toxoplasmes dans un cas de chorioretinite sero-negative. Ophthalmologica, 147, 273-281.

Friedenwald, H. (1902). Acute circumscribed exudative chorioretinitis. Transactions of the American Ophthalmic Society, 9, 577-588.

Griffiths, H. (1897). In System of Diseases of the Eye, vol. III, p. 355. Edited by W. F. Norris, and C. A. Oliver. Lippincott: London and Philadelphia.

Hilton, A. L., Richmond, S. J., Milne, J. D., Hindley, F., and Clarke, S. K. R. (1974). Chlamydia A in the female genital tract. British Journal of Venereal Diseases, 50, 1-10.

Mardh, P. A., Ripa, K. T., Svensson, L., and Westrom, L. (1977). Chlamydia trachomatis infection in patients with acute salpingitis. New England Journal of Medicine, 296, 1377-1579.

Muller-Shoop, J. H., Wang, S. P., Munzinger, J., Schlapfer, H. U., Knoblauch, M., and Ammann, R. W. (1978). Chlamydia trachomatis as a possible cause of peritonitis and perihepatitis in young women. British Medical Journal, 1, 1022-1024.

Perkins, E. S. (1961). Uveitis and Toxoplasmosis. Churchill: London.

Perkins, E. S. (1973). Ocular toxoplasmosis. British Journa of Ophthalmology, 57, 1-17.

Public Health Laboratory Statistics (1969). 83, 131. London.

Treharne, J. D., Darougar, S., and Jones, B. R. (1977a). Modification of the micro-immunofluorescence test to provide a routine serodiagnostic test for chlamydial infection. Journal of Clinical Pathology, 30, 510-517.

Treharne, J. D., Dines, R. J., and Darougar, S. (1977b). Serological responses to chlamydial ocular and genital infections in the United Kingdom and Middle East. In Nongonococcal Urethritis and Related Infections, pp. 249358. Edited by D. Hobson and K. K. Holmes. American Society for Microbiology: Washington.

Treharne, J. D., Ripa, K. T., Mardh, P. A., Svensson, L., Westrom, L., and Darougar, S. (1979). Antibodies to Chlamydia trachomatis in acute salpingitis. British Journal of Venereal Diseases, in press.

Wang, S. P., and Grayston, J. T. (1975). Chlamydia trachomatis serotype ' $\mathrm{J}$ '. Journal of Immunology, 115, 1711-1715. 